\title{
CFD STUDY OF THE EFFECT OF ADDITIONAL INNER BLADES ON SAVONIUS ROTOR PERFORMANCE
}

\author{
Hassan Zenhom Haddad *, Khairy Elsayed $\uparrow+\uparrow$, Yasser Shabana $\ddagger$ \\ hassanzenhom1@gmail.com, kelsayed75@gmail.com, \\ yasser.shabana@gmail.com
}

\begin{abstract}
The effect of adding inner blades to the Savonius turbine deserves extensive attention due to its promising enhancement to its performance. A numerical study was carried out to investigate the effects of different radii and angles of additional inner blades on the performance of Bach-type rotor at different tip speed ratio (TSR). In the present work, two different studies were performed for a number of cells, domain size and time step. The best numerical model was then used to investigate the effect of the additional inner blades on the Savonius rotor performance. Additional inner blades radii and angles were investigated from 0.25 to 0.85 times original blade radius and $70^{\circ}$ to $160^{\circ}$ respectively. The best improvement of rotor performance with additional inner blades are higher than values of conventional one by $27.77 \%$ at tip speed ratio TSR $=0.75$ up to $44.5 \%$ at $\mathrm{TSR}=0.25$.
\end{abstract}

\section{KEYWORDS: Wind turbine; Savonius; Inner blades; CFD}

\section{INTRODUCTION}

Recently, there has been an increase in the global anxiety with the indiscriminate exploitation of non-renewable energy resources. Pollution, global warming and reduction of political and economic viability in the use of non-renewable energy resources are some consequences of this exploitation. The use of renewable energy and decentralized power generation are alternatives to reduce the exploitation of conventional energy resources and its impacts.

Savonius turbines can be an interesting technological alternative to conventional wind turbines. Several studies, experimental, theoretical or numerical, on that device are found in technical and scientific literature. Different arrangements of Savonius rotor were studied, and each configuration provides different performance

\footnotetext{
* MSC Student, Mechanical Power Engineering Department, Helwan University, Faculty of Engineering at El-Mataria, Masaken ElHelmia P.O. Cairo 11718, Egypt.

$\uparrow$ Associate Professor, Mechanical Engineering Department, college of Engineering and Technology-Smart Village Campus, Arab Academy for Science, Technology and Marine Transport. (AASTMT), P.O. Box 12676, Giza, Egypt.

$\dagger \dagger$ Associate Professor, Mechanical Power Engineering Department, Helwan University, Faculty of Engineering at El-Mataria, Masaken ElHelmia P.O. Cairo 11718, Egypt.

\$ Professor and chairman, Mechanical Design Department, Faculty of Engineering at Mattaria, Helwan University, Egypt.
} 
[1]. The use of multiple quarter blades increases the maximum Power Coefficient $\left(\mathrm{C}_{\mathrm{p})}\right.$ by $8.89 \%$ [2] and using layered multiple miniature blades increase the maximum $\mathrm{C}_{\mathrm{p}}$ by $11.34 \%$ compared with no multiple quarter [3]. Al-Ghriybah et al. [4] also investigated the effect of the additional inner blade position on the performance of the Savonius rotor.

Altan et al. [5] showed that adding straight blade increased Cp by $20 \%$.

Using both upper and lower circular end plates increased $\mathrm{C}_{\mathrm{p}}$ by $36 \%$ over the conventional configuration [6].

The non-vented elliptical-bladed rotor has $\mathrm{C}_{\mathrm{p}}$ greater than that of the conventional semi-circular-bladed rotor by $16.31 \%$ and the vented elliptical-bladed rotor has $C_{p}$ greater than that of the conventional semi-circular-bladed rotor by $23.06 \%$ [7].

The peak $\mathrm{C}_{\mathrm{p}}$ of the three-rotor Savonius turbine with rotors arranged in a triangular pattern is approximately $44 \%$ higher than that of the single rotor design [8]. The developed three turbine cluster has an average $C_{p}$ up to $34 \%$ higher than that of an isolated turbine [9]. For a Savonius wind farm consisting of 12 turbines, a 30\% increase in $C_{p}$ is obtained compared to an isolated Savonius turbine [10]. The overall $\mathrm{C}_{\mathrm{p}}$ for the two-turbine system can be increased by $40 \%$ over that of a single isolated turbine [11]. An increase of $19 \%$ in farm efficiency is obtained when the number of turbines was increased from 2 to 16 [12].

Adding four deflector blades gives a $\mathrm{C}_{\mathrm{p}}$ enhancement ratio of $10.16 \%$ at TSR equals to 0.5 [13].

In this research study, the performance of a Savonius Bach-type rotor with additional inner blades is investigated. The Bach-rotor profile used is $\left(D_{r}=230 \mathrm{~mm}\right.$, $\mathrm{p} / \mathrm{q}=0.2, \psi=124^{\circ}$ without overlap or gap) as used by Kamoji et al. [14] as shown in Fig. 1. a.

Inner blades are added in this study which is inspired from multiple quarter blades investigated by [2,3] and additional inner blades suggested by [5], different concentric additional blades radius values ( $\mathrm{r} / \mathrm{R}$ ) and angles $\beta$ ranged from 0.25 to 0.85 times original blade radius and $70^{\circ}$ to $120^{\circ}$ starting from blade tip and from $130^{\circ}$ to $160^{\circ}$ starting after $4^{\circ}$ from blade root respectively as shown in Fig. $1 . \mathrm{b}$ were all investigated first at TSR $=0.75$ to obtain the best configuration which is studied after that at different TSRs from 0.2 to 1.3 . 


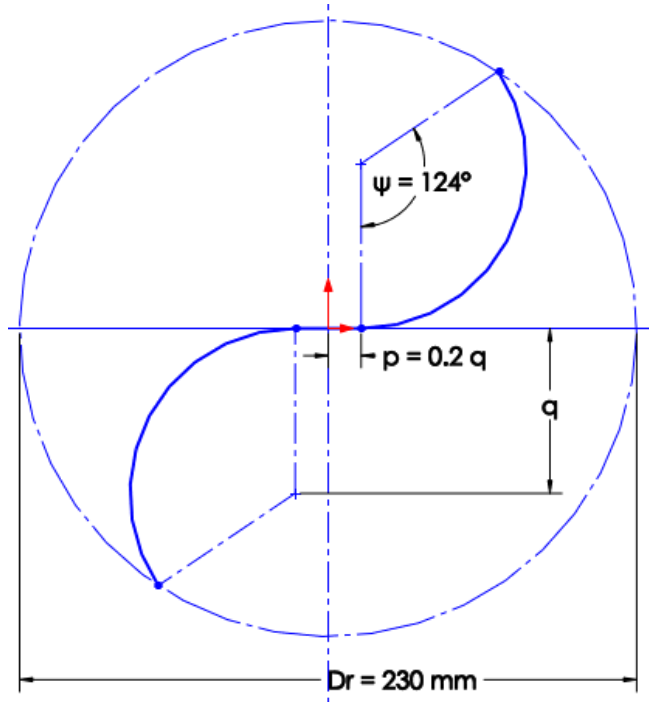

(a) Conventional Bach-type Savonius rotor.

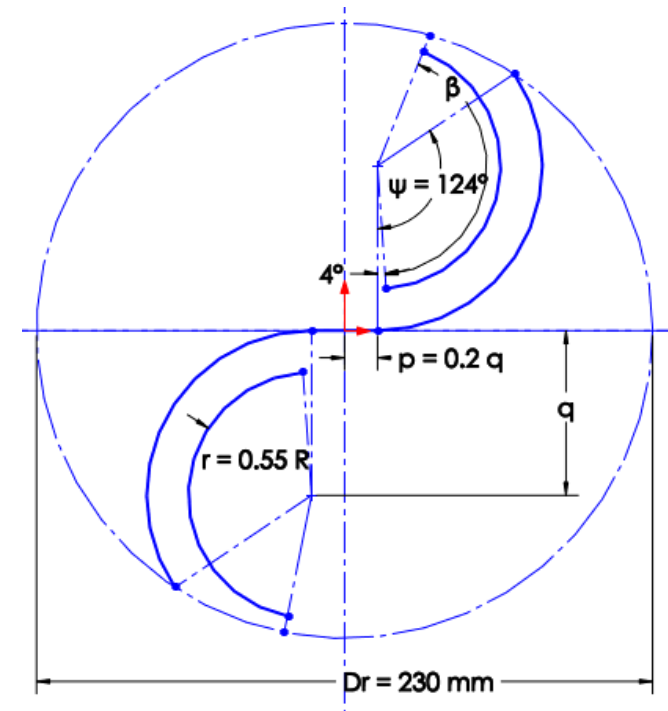

(b) Modified Bach-type Savonius rotor with additional blades.

Figure 1: Geometry and dimensions of Bach-type Savonius rotor used in the present study

\section{Modelling and validation}

\subsection{CFD modelling}

Reynolds-averaged Navier-Stokes (RANS) method was utilized. k- $\epsilon$ realizable turbulence model with enhanced wall treatment. The "Curvature correction" option is enabled. Spatial discretization of gradient is set to "least squares cell based" and for pressure is set to "second order" which provide improved accuracy over the "standard" and "linear" scheme [15]. For momentum, turbulent kinetic energy and turbulent dissipation rate the spatial discretization is set to "second order upwind". Transient formulation is set to "second order implicit". To improve the start-up and the general solution behaviour of flow simulation, the option "high order term relaxation" is enabled [15].

Solution under relaxation factors are kept to their default values. Sliding mesh model (SMM) is used to solve all cases which is a transient model, but the moving reference frame model - which is a steady model - is used to initialize the solution before starting SMM solution. Wind speed used is $9 \mathrm{~m} / \mathrm{s}$ and Re is 150,000 (based on $\mathrm{D}_{\mathrm{r}}$ ) [14].

The domain consists of rotating and stationary regions with interface circular edge between them, and for more flexibility to control the mesh quality and the number of cells, the domain is separated into blocks as shown in Fig. (2.a). 
(a) Computational domain

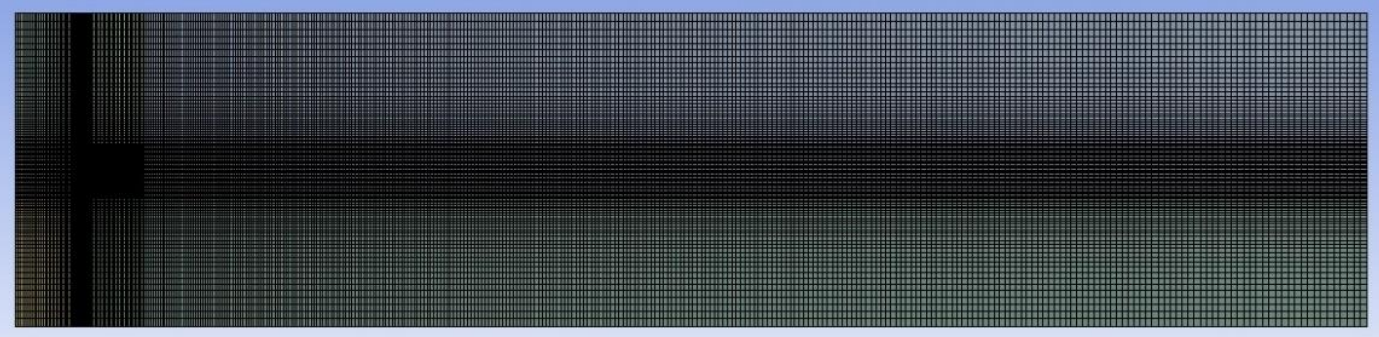

(b) Mesh of the whole domain

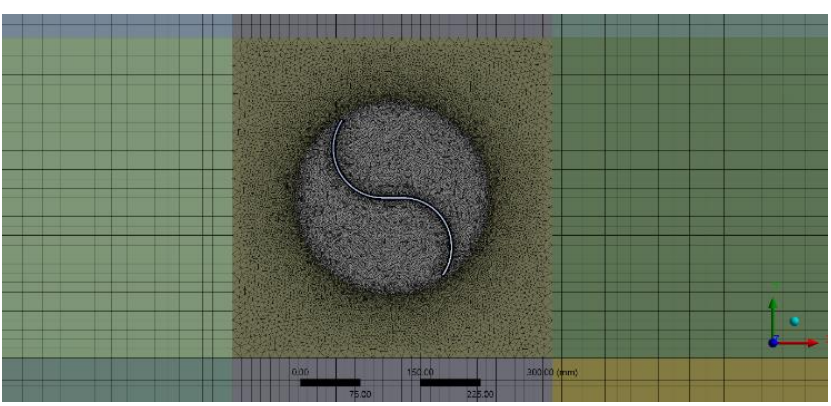

(c) Structured and unstructured mesh regions

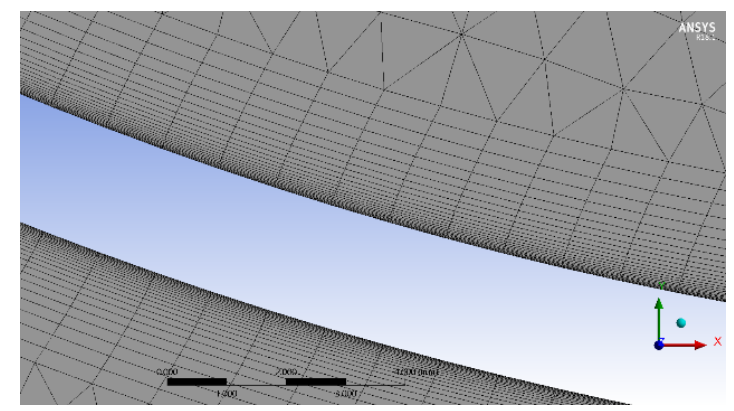

(d) Zoom around the moving blades.

Figure 2: Computational domain and mesh.

Rotating region is made as one surface with structured quadrilateral cells around the rotor edges with inflation in order to obtain the required $y+$ value, to be about 1 as shown in Fig. (2.b). Stationary region is separated into nine surfaces, all of them with structured quadrilateral cells, except the part around the rotating zone as shown in Figs. (2.c) and (2.d).

To avoid interpolation error results from non-conformal mesh (where the cells' edges are not aligned with each other at the interface), a conformal mesh at the interface between rotating and stationary zones is made by dividing the interface edge into equal divisions as a function of the time step angle. So, for a time step 
equivalent to $0.5^{\circ}$ of rotor rotation, the interface edge is separated into 720 equal divisions as shown in Fig. (2.b). By this way, the mesh at the interface is maintained conformal while rotor rotating.

As shown in Fig. 3, domain dimensions "width", "inlet width", "upstream", and "downstream" are functions of reference dimensions. The reference dimension is $\mathrm{D}_{\text {r. }}$ Inlet surface with $400 \mathrm{~mm}$ width is set to "velocity inlet" by a magnitude of 9 $\mathrm{m} / \mathrm{s}$ magnitude as used by Kamoji et al. [14]. The outlet surface is set to "pressure outlet" by a magnitude of 0 pa gage pressure. To simulate the wind tunnel, the two edges adjacent to "velocity inlet" edge are set to "pressure inlet" by a magnitude of $0 \mathrm{~Pa}$ gage pressure. The sides surfaces are set to "symmetry" as shown in Fig. 4.

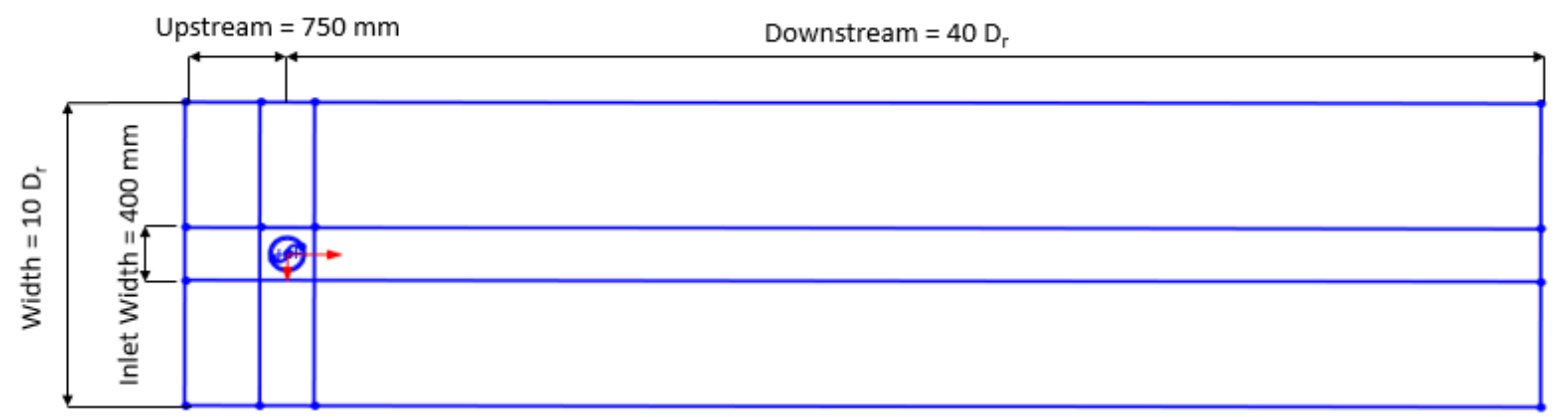

Figure 3: Domain Extents.

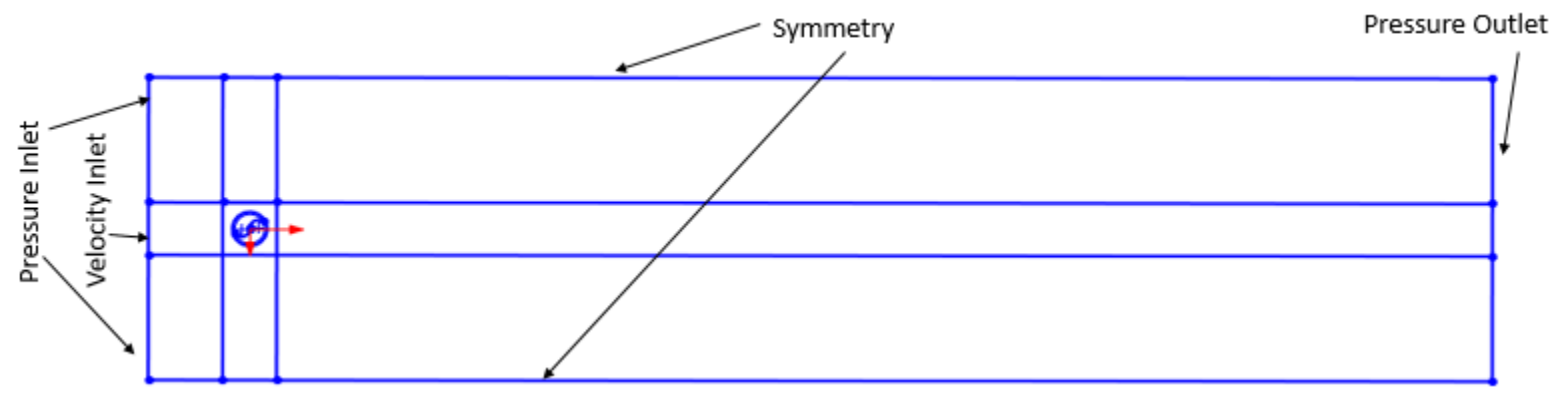

Figure 4: Boundary conditions.

\subsection{Mesh independence study}

Three models were investigated with different number of cells are all with time step angle of $0.5^{\circ}$ and domain size of $750 \mathrm{~mm}$ upstream, $400 \mathrm{~mm}$ inlet width, $10 \mathrm{Dr}$ width, and 40 Dr downstream [13].

Table 1 lists the obtained $\mathrm{C}_{\mathrm{p}}$ values at different number of cells.

Table 1: Number of cells independent study

\begin{tabular}{|c|c|c|}
\hline Grid Level & Number of Cells & $\mathrm{C}_{\mathrm{p}}$ \\
\hline 1 & 338,984 & $19.37 \%$ \\
\hline 2 & 114,611 & $18.94 \%$ \\
\hline 3 & 101,981 & $17.85 \%$ \\
\hline 4 & 51,950 & $16.95 \%$ \\
\hline
\end{tabular}


Where the change between the grid levels two and one is marginal, so 114,611 elements grid is selected to adopt all simulations.

\subsection{Validation}

The final characteristic curve of the Bach-type rotor is obtained by using seven values of TSR (from 0.2 to 1.3) and Fig. 5 shows a comparison between theobtained numerical results and the experimental ones of Kamoji et al. [14]. It can be seen that the obtained maximum $\mathrm{C}_{\mathrm{p}}$ equals $18.94 \%$ which is very close to the experimental one at the same TSR of 0.75 .

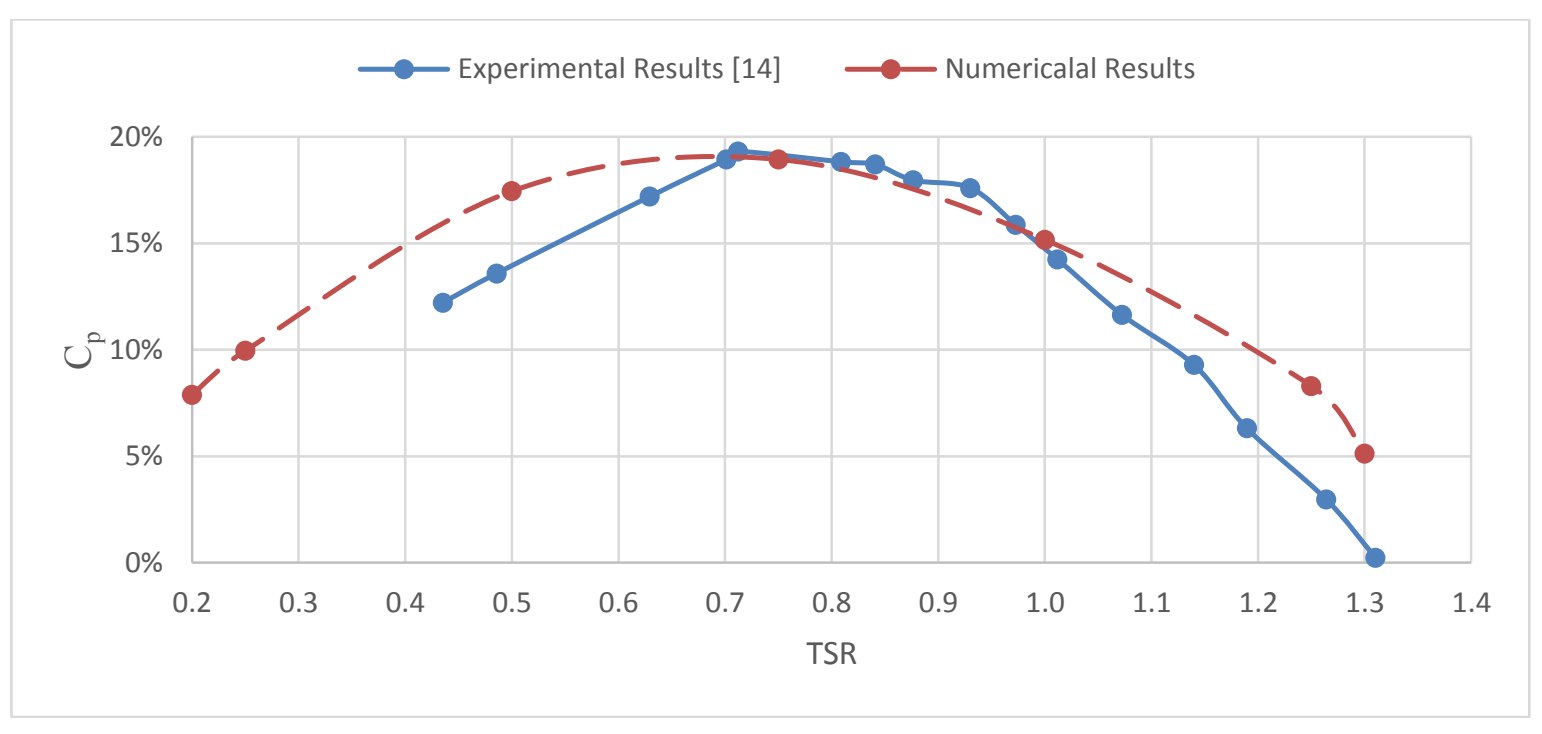

Figure 5: Validation curve.

\section{Results and discussion}

With the intention of improving the aerodynamic performance of a two-bladed Savonius rotor, the present investigation attempts to explore the performance of Savonius rotor with additional inner blades. Two-dimensional unsteady simulations were conducted for Savonius rotor with additional inner blades at wind speed of 9 $\mathrm{m} / \mathrm{s}$. The power coefficient $(\mathrm{Cp})$ is calculated with respect to the tip speed ratio (TSR) of 0.75 . Two geometrical parameters of the additional inner blades were investigated, namely, $\mathrm{r} / \mathrm{R}$ and $\beta$.

\subsection{Effect of $\mathbf{r} / \mathbf{R}$ on $\mathbf{C}_{\mathrm{p}}$}

The radius of additional inner blade with constant $\beta=120^{\circ}$ and TSR of 0.75 is investigated. Nine different inner blade radius values (r/R), which are $0.25,0.30$, $0.35,0.50,0.55,0.60,0.65,0.80$, and 0.85 , were adopted. There was an enhancement in the conventional power coefficient $\left(\mathrm{C}_{\mathrm{p}}\right)$ when using the inner blades. As shown in Fig. 6, the highest $\mathrm{C}_{\mathrm{p}}$ of 0.2298 is gained at the optimum inner 
blade radius of $(r / R=0.55)$. The power coefficient $\left(C_{p}\right)$ improved with all inner blade radius values, and starting from $0.25\left(\mathrm{C}_{\mathrm{p}}\right)$ increased until 0.55 but from 0.60 to $0.85\left(\mathrm{C}_{\mathrm{p}}\right)$ decreased but still higher than the conventional $\mathrm{C}_{\mathrm{p}}$ of 0.1894 .

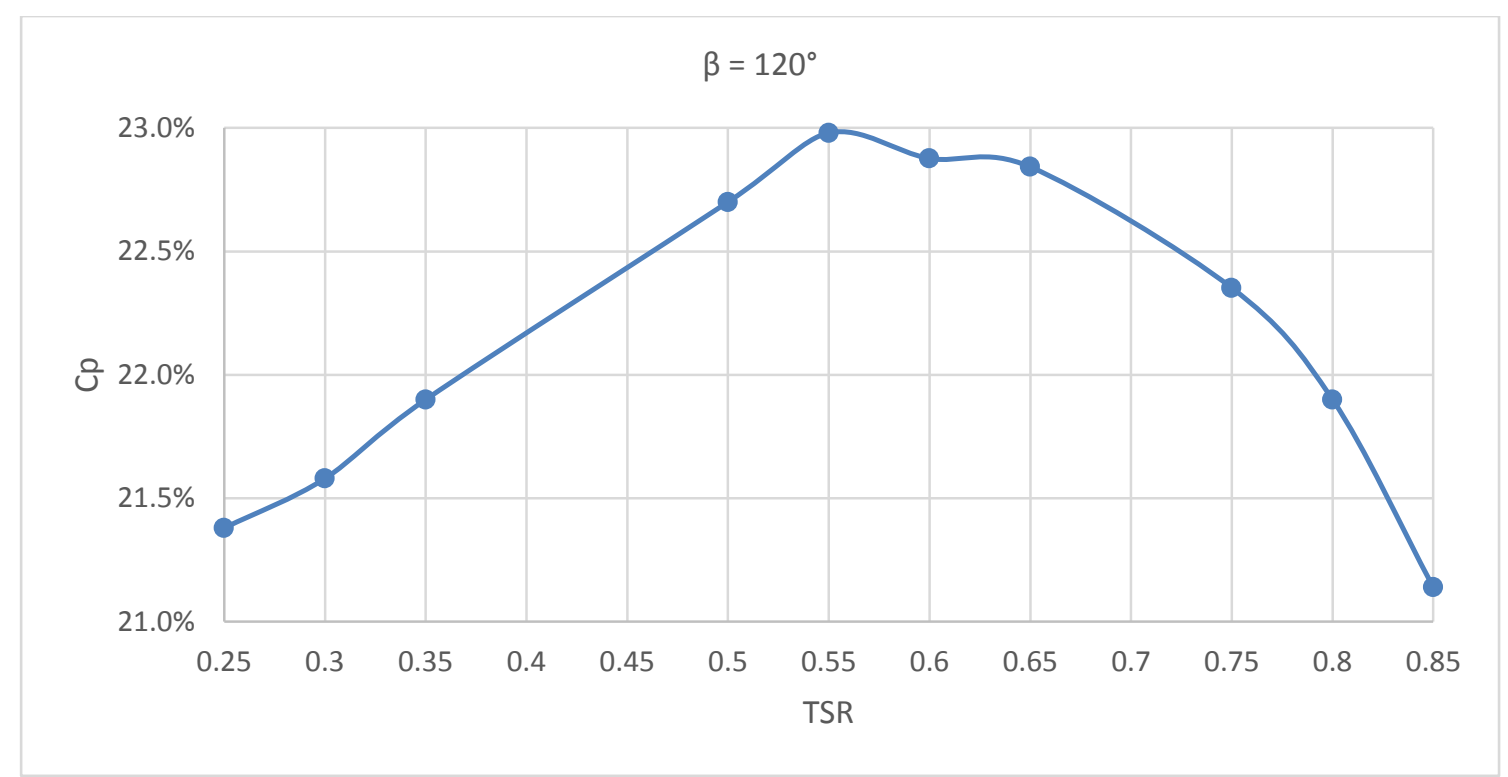

Figure 6: Influence of $(r / R)$ on $C p$ at $\beta=120^{\circ}$.

\subsection{Effect of $\beta$ on $\mathrm{Cp}$}

Then, the best geometry gained from the above study $(\mathrm{r} / \mathrm{R}=0.55)$ is used to investigate the effect of the angle of additional inner blade from $70^{\circ}$ to 160 at constant TSR of 0.75 .

Ten different inner blade angles, from $70^{\circ}$ to $160^{\circ}$ with $10^{\circ}$ step were adopted. As shown in Fig. $7, \mathrm{C}_{\mathrm{p}}$ with all of these angles is larger than the rotor without additional inner blades starting from $\beta=70^{\circ}$ which has $C_{p}=0.2085, C_{p}$ increased until $\beta=150^{\circ}$ to be 0.242 , but with $\beta=160^{\circ}, C_{p}$ was only 0.239 .

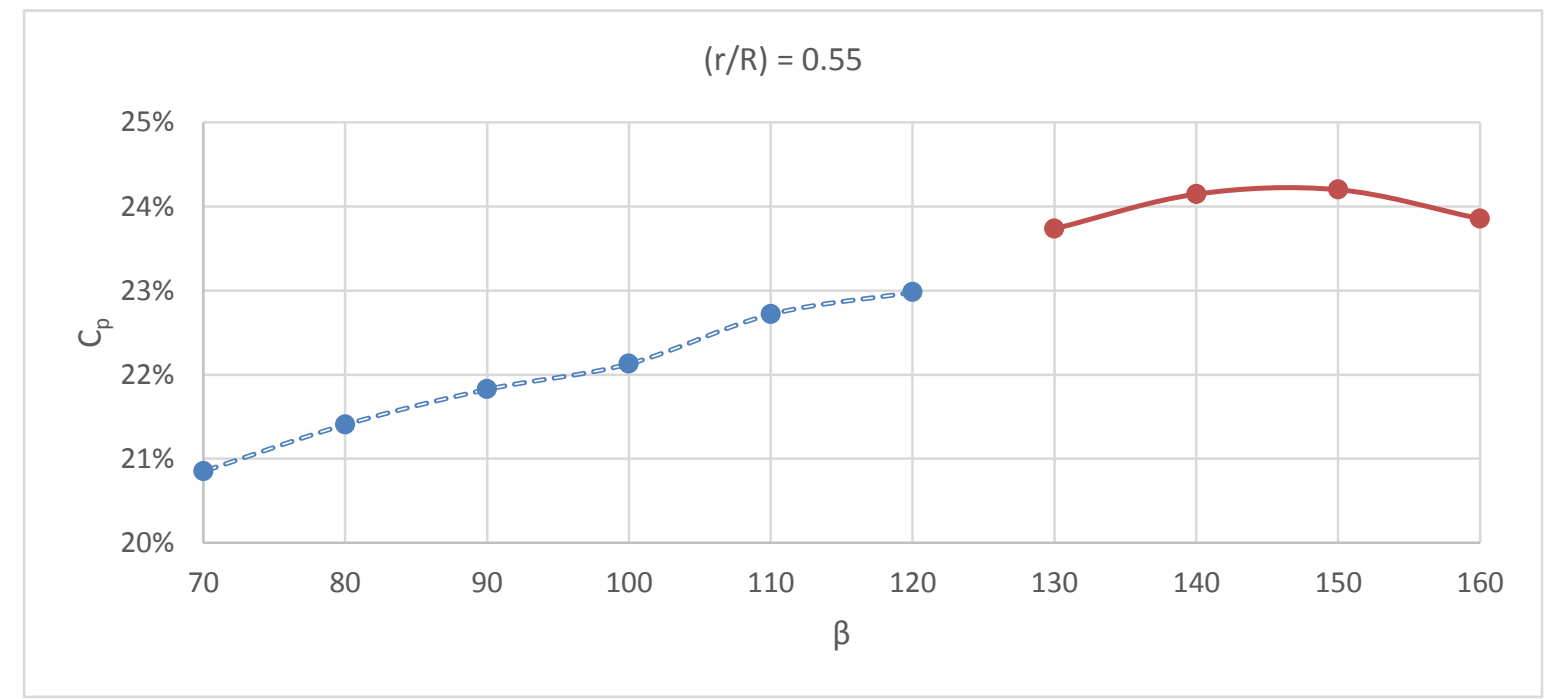

Figure 7: Influence of $\beta$ on $C p$ at $(r / R)=0.55$. 


\subsection{Optimizing best geometry of rotor with additional inner blades}

As clarified in the investigations, the optimum geometry of the rotor with additional inner blades is that with $(\mathrm{r} / \mathrm{R})=0.55$ and $\beta=150$ which achieved $\mathrm{C}_{\mathrm{p}}=$ 0.242 . This configuration then investigated at different TSR values and as shown in Fig. 8, the maximum $\mathrm{C}_{\mathrm{p}}$ is 0.242 and achieved at TSR $=0.75$, but Fig. 9 shows that the maximum performance enhancement is $44.58 \%$ which achieved at TSR $=0.25$.

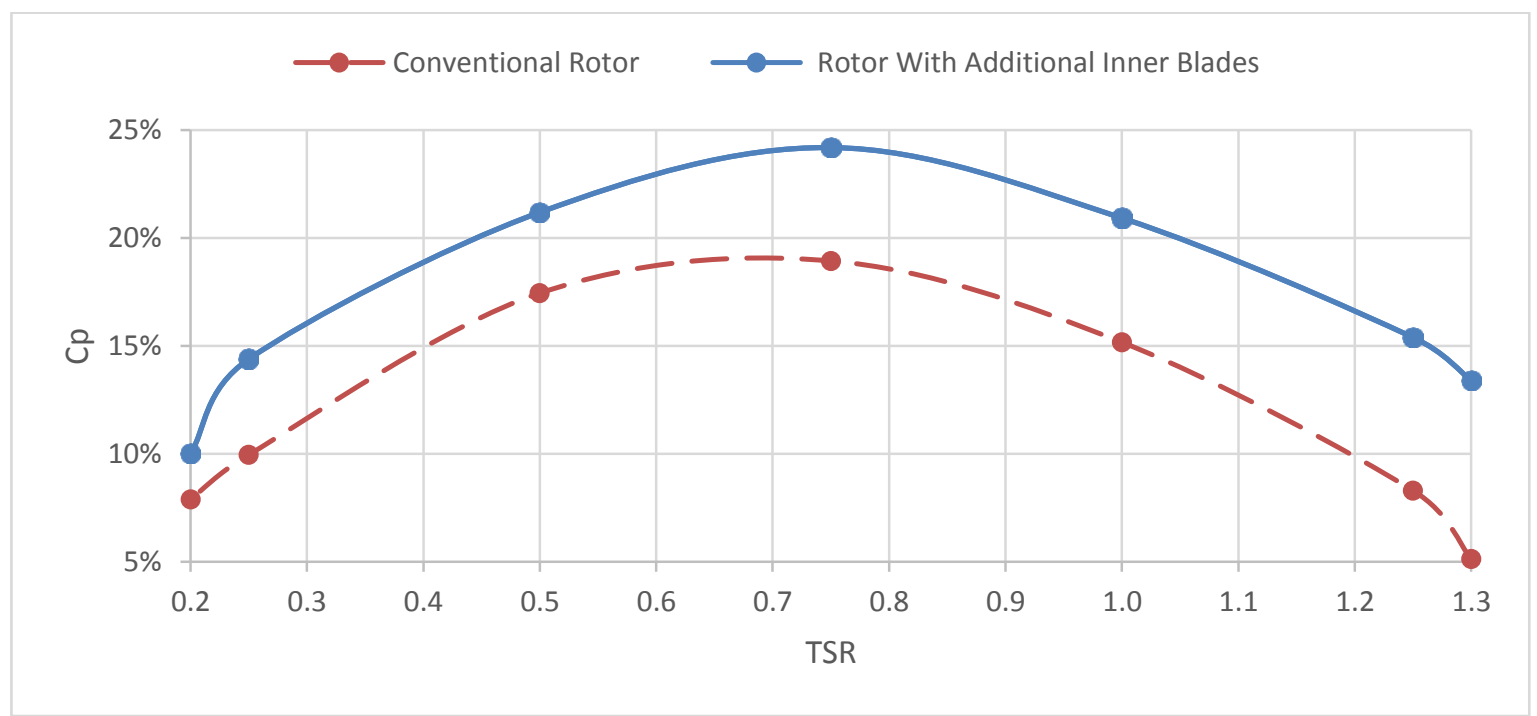

Figure 8: Characteristic curves of conventional rotor and rotor with additional inner blades at $(\mathrm{r} / \mathrm{R})=\mathbf{0 . 5 5}$ and $\beta=150^{\circ}$.

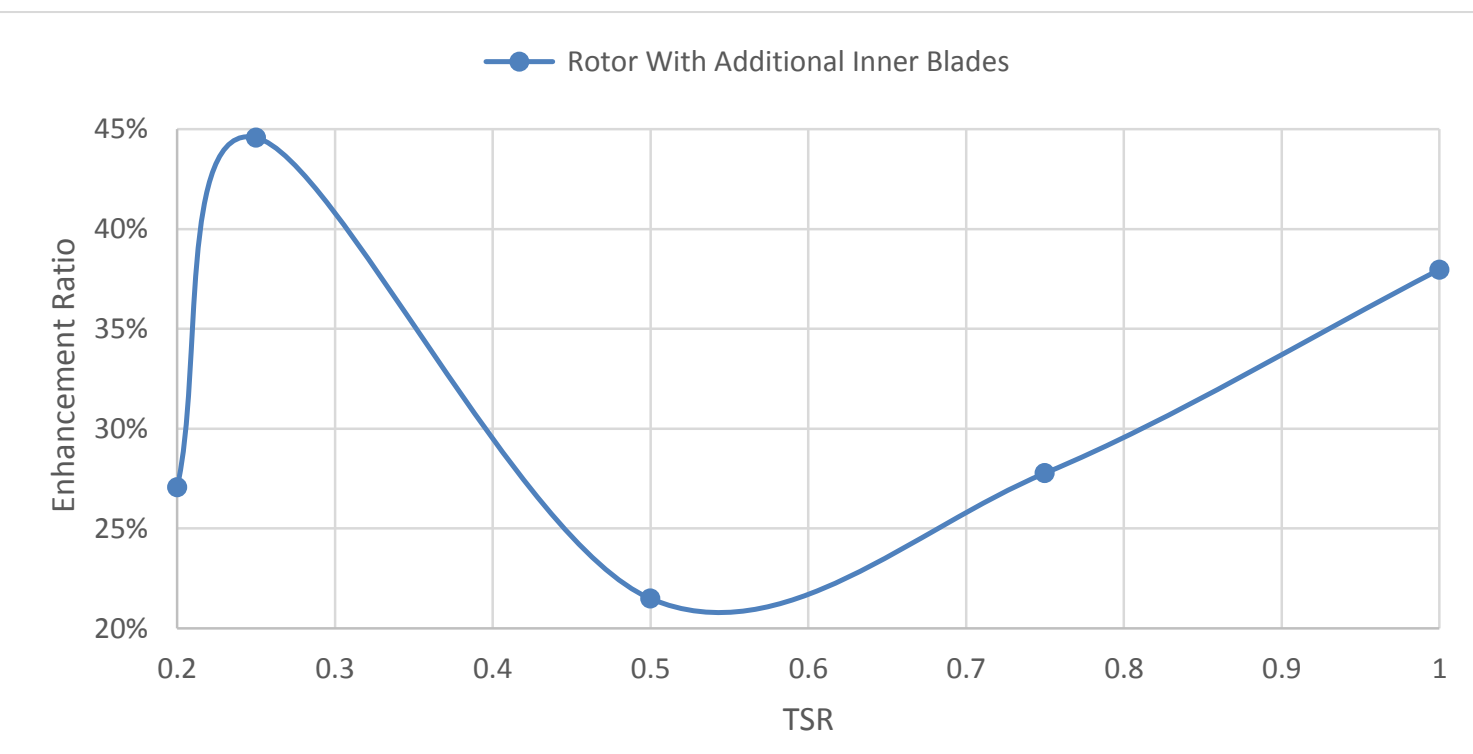

Figure 9: Enhancement ratios of rotor with additional inner blades at $(\mathbf{r} / \mathbf{R})=0.55$ and $\beta=150^{\circ}$ over conventional rotor. 


\section{Conclusions}

This study presents a numerical investigation using a software ANSYS FLUENT of a Savonius wind rotor with additional inner blades with various radii and angles to evaluate the performance of the new rotor. Additional inner blades with radii range from $\mathrm{r} / \mathrm{R}=0.25$ to 0.85 and angles range from $\beta=$ concentric $70^{\circ}$ to $160^{\circ}$ are investigated at $\mathrm{TSR}=0.75$. The $\mathrm{r} / \mathrm{R}$ parameter firstly was investigated at fixed value of $\beta=120^{\circ}$ then, the second parameter $\beta$ is investigated for a fixed value of $\mathrm{r} / \mathrm{R}$ corresponding to maximum $\mathrm{C}_{\mathrm{p}}$ determined from the first study.

The best configuration with values of $r / R$ and $\beta$ achieved the maximum $C_{p}$ then investigated at different TSRs to obtain the maximum $\mathrm{C}_{\mathrm{p}}$ and the maximum performance enhancement of the rotor with additional inner blades over the conventional one.

The achievements of this study could be summarized as follows:

1. The optimum value of $r / R$ is 0.55 which achieved the maximum $C_{p}=0.2298$ and 0.242 at $\beta=120^{\circ}$ and $150^{\circ}$ respectively at TSR $=0.75$.

2. The maximum $C_{p}$ increased with increasing $\beta$ from $70^{\circ}$ to $150^{\circ}$, but at $\beta=160^{\circ}$ $\mathrm{C}_{\mathrm{p}}$ started to decrease, so with $\beta=150^{\circ}$ is the optimum blade angle.

3. The maximum performance enhancement is $44.58 \%$ over the conventional rotor which achieved with having lower $\mathrm{C}_{\mathrm{p}}=0.144$ at $\mathrm{TSR}=0.25$.

\section{Nomenclature}

$\begin{array}{ll}\mathrm{A} & \text { Rotor area projected to the wind }(\mathrm{m} 2) \\ \mathrm{Cp} & \text { Rotor power coefficient }\left(\frac{\mathbf{T} \times \boldsymbol{\omega}}{\mathbf{1} \mathbf{2} \times \boldsymbol{\rho} \times \mathbf{A} \times \boldsymbol{V}^{3}}\right) \\ \mathrm{Dr} & \text { Rotor diameter }(\mathrm{m}) \\ \mathrm{Lmax} & \text { Maximum length of stator }(\mathrm{m}) \\ \mathrm{p} / \mathrm{q} & \text { Blade shape factor for Bach-type rotor } \\ \mathrm{R} & \text { Rotor radius }(\mathrm{m}) \\ \mathrm{Re} & \text { Reynolds number }(\rho . \mathrm{V} . \mathrm{Dr} / \mu) \\ \mathrm{r} & \text { Additional inner blade radius }(\mathrm{mm}) \\ \mathrm{T} & \text { Rotor output torque }(\mathrm{N} . \mathrm{m}) \\ \mathrm{V} & \text { Wind speed }(\mathrm{m} / \mathrm{s}) \\ \mathrm{y}+ & \text { Dimensionless distance to the wall } \\ \mathrm{Greek} \mathrm{symbols} & \\ \beta & \text { Additional inner blade angle }\left({ }^{\circ}\right) \\ \mu & \text { Dynamic viscosity of the air }(\mathrm{kg} / \mathrm{m} . \mathrm{s}) \\ \rho & \text { Density of the air }(\mathrm{kg} / \mathrm{m} 3) \\ \psi & \text { Blade arc angle for Bach-type rotor angle }\left(^{\circ}\right) \\ \omega & \text { Rotor rotational speed }(\mathrm{rad} / \mathrm{s})\end{array}$

Abbreviations 


$\begin{array}{ll}\text { B.C } & \text { Boundary condition } \\ \text { CFD } & \text { Computational fluid dynamics } \\ \text { k- } \epsilon & \text { Turbulence kinetic energy - turbulent dissipation } \\ \text { RANS } & \text { Reynolds-averaged Navier-Stokes } \\ \text { TSR } & \text { Tip-speed ratio }\end{array}$

\section{References}

[1] Akwa, J. V., Vielmob,H. A., and Petryb, A. P. (2012). "A review on the performance of Savonius wind turbines". Journal of Renewable and Sustainable Energy Reviews; 16(5), 3054- 3064.

[2] Sharma, S. and Sharma, R. K. (2016). "Performance improvement of Savonius rotor using multiple quarter blades - A CFD investigation". Journal of Energy Conversion and Management; 127, 43-54.

[3] Sharma, S. and Sharma, R. K. (2017). "CFD investigation to quantify the effect of layered multiple miniature blades on the performance of Savonius rotor". Journal of Energy Conversion and Management; 144, 275-285.

[4] Al-Ghriybah, M., Zulkaflia, M., F., Didane, D. H., and Mohd, S. (2019). "The effect of inner blade position on the performance of the Savonius rotor". Journal of Sustainable Energy Technologies and Assessments; 36, 100534.

[5] Altan, B. D., Altan, G., and Kovan, V. (2016). "Investigation of 3D printed Savonius rotor performance". Journal of Renewable Energy; 99, 584-591.

[6] Jeon, K. S., Jeong, J. I., Pan, J., and Ryu, K. (2015). "Effects of end plates with various shapes and sizes on helical Savonius wind turbines". Journal of Renewable Energy; 79, 167-176.

[7] Alom, N. and Saha, U. K. (2018). "Performance evaluation of vent-augmented elliptical-bladed Savonius rotors by numerical simulation and wind tunnel experiments". Journal of Energy; 152, 277-290.

[8] El-Baz, A.R., Youssef, K., and Mohamed M.H. (2016). "Innovative improvement of a drag wind turbine performance". Journal of Renewable energy; 86, 89-98.

[9] Shaheen, M., El-Sayed, M., and Abdallah, S. (2015). "Numerical study of two-bucket Savonius wind turbine cluster".Journal of Wind Engineering and Industrial Aerodynamics; 173, 78-89.

[10] Zheng, Y., Bai, H. L., and Chan, C. M. (2019). "Optimization of Savonius turbine clusters using an evolutionary based genetic algorithm". Journal of Energy Procedia; 158, 637-642.

[11] Bai, H., and Chan C. (2019). "Positive interactions of two Savonius-type vertical-axis wind turbines for Performance improvement". Journal of Energy Procedia; 158, 625-630.

[12] Mereu, R., Federici, D., Ferrari, G., Schito, P., and F. Inzoli. (2017). " Parametric numerical study of Savonius wind turbine interaction in a linear array". Journal of Renewable energy; 113, 1320-1332. 
[13] Saad El-Deen, A. E., Abd El-Maksoud, R. M., Nawar, M.A.A., and Attai. Y. A. (2018). "A Numerical study of the effet of stator on Savonius Bach-type rotor Performance". Proceedings of ICFD13: Thirteenth International Conference of Fluid Dynamics.

[14] Kamoji, M. A., Kedare, S. B., and Prabhu, S. V. (2009). "Experimental investigations on single stage modified Savonius rotor". Journal of Applied Energy; 86(7-8), 1064-1073.

[15] ANSYS Fluent Theory Guide Release 15.0. ANSYS, Inc.; 2013. 